\title{
PENERAPAN ALGORITMA NEAREST NEIGHBOR DALAM MEMPREDIKSI KELAYAKAN PENERIMAAN KARTU KREDIT PADA BANK CIMB NIAGA
}

\author{
Eferoni Ndruru', Taronisokhi Zebua ${ }^{2}$ \\ STMIK Budi Darma, Medan, Sumatera Utara, Indonesia. \\ ${ }^{1}$ ronindruru@gmail.com, ${ }^{2}$ taronizeb@gmail.com
}

\section{ABSTRACT}

Credit card application is a financial facility that allows a person or business entity to borrow money to buy a product and pay it back within a specified time. Credit card manufacture often experiences risk in providing credit, both moderate, good and very good risk, due to lack of data analysis and lack of attention. So the purpose of this study is to analyze the risks that often occur in making credit cards. And provide efficient solutions. In solving this problem, it is necessary to apply the method. The method used in this study is Nearest Neighbor. The Nearest Neighbor algorithm is an approach to finding cases by calculating the proximity between new cases (testing data) and old cases (training data), which is based on matching the weights of a number of existing features. Therefore, it can be applied in analyzing old customer data with data new so that comparisons can be made whether or not it is eligible to receive credit. The results obtained in this study are the results of testing systems and methods by producing a level of risk.

Keyword : Data Mining, Grouping, clustering

\section{PENDAHULUAN}

Pada dunia perbankan pemberian kartu kredit kepada nasabah merupakan hal yang sulit dan dengan resiko yang sangat tinggi. Dalam pengajuannya, harus analisis data yang jelas dan tidak pernah mengalamami masalah ke bank yang lain. Dan berkas yang meyakinkan pihak bank untuk memberikan kartu kredit seperti data pekerjaan, penghasilan perbulan, tempat tinggal usia dan masih banyak yang perlu dipertimbang oleh bagian analisis bank. Oleh karna itu banyak nasabah yang gagal dan pihak bank salah untuk menganalisis sehingga mengakibatkan kerugian yang besar seperti macet, lari nasabah. Maka dengan masalah tersebut perlu menggunakan sistem prediksi yang jelas dan yang bisa dipercayai kepada bagian analisis bank. maka dibangun sistem prediksi penerapan algoritma Nearest Neighbor dalam memprediksi kelayakan penerimaan kartu kredit.

Algoritma nearset neighbor adalah merupakan sebuah algoritma klasifikasi dan prediksi terhadap sekumpulan data berdasarkan sekumpulan data yang sudah terklasifikasi sebelumnya. Algoritma nearset neighbor ini merupakan metode data mining yang dapat meprediksi dan mengklasifikasikan data[1].

Data mining adalah suatu proses penambangan suatu informasi penting dari suatu data. Data mining sering digunakan dalam mengklasifikasikan data yang besar karena mampu untuk mengubah data yang besar menjadi model ilmu pengetahuan yang baru

\section{METODE}

Data adalah catatan atas kumpulan fakta. Data merupakan bentuk jamak dari datum, berasal dari bahasa Latin yang berarti "sesuatu yang diberikan".
Dalam penggunaan sehari-hari data berarti suatu pernyataan yang diterima secara apa adanya. Pernyataan ini adalah hasil pengukuran atau pengamatan suatu variabel yang bentuknya dapat berupa angka, kata-kata, atau citra. Dalam keilmuan (ilmiah), fakta dikumpulkan untuk menjadi data. Data kemudian diolah sehingga dapat diutarakan secara jelas dan tepat sehingga dapat dimengerti oleh orang lain yang tidak langsung mengalaminya sendiri, hal ini dinamakan deskripsi. Pemilahan banyak data sesuai dengan persamaan atau perbedaan yang dikandungnya dinamakan klasifikasi[2].

\section{Metode Nearset Neighbor}

Algoritma Nearest Neighbor adalah pendekatan untuk mencari kasus dengan menghitung kedekatan antara kasus baru testing data) dengan kasus lama (training data), yaitu berdasarkan pada pencocokan bobot dari sejumlah fitur yang ada. Jenis algoritma Nearest Neighbor ada 2, yaitu:

1. 1-NN, yaitu pengklasifikasikan dilakukan nterhadap 1 label data terdekat.

2. 2. KNN, yaitu pengklasifikasikan dilakukan terhadap $k$ label data terdekat

3. Distance Euclidean Distance sering digunakan untuk menghitung jarak. Euclidean Distance berfungsi menguji ukuran yang bisa digunakan sebagai interpretasi kedekatan jarak antara dengan> 1 [3].

KNN adalah suatu metode yang menggunakan algoritma supervised dimana hasil dari query instance yang baru diklasifikasikan berdasarkan mayoritas dari label class pada KNN. Tujuan dari algoritma KNN adalah mengklasifikasikan objek baru berdasarkan atribut dan training data [1]. Algoritma 
KNN bekerja berdasarkan jarak terpendek dari query instance ke training data untuk menentukan KNNnya. Salah satu cara untuk menghitung jarak dekat atau jauhnya tetangga menggunakan metode Euclidean dua obyek, Persamaan merupakan rumus Euclidean Distance[3]. Algoritma nearest neighbor merupakan pendekatan untuk mencari kasus dengan kedekatan antara kasus baru dengan kasus lama, yaitu berdasarkan pada kecocokan bobot sejumlah fitur yang ada. Metode ini mencari jarak terhadap tujuan dari data yang telah disimpan sebelumnya. Setelah didapatkan jaraknya kemudian dicari jarak terdekat. Jarak terdekat tersebut yang digunakan untuk mencari identitas tujuan [3].

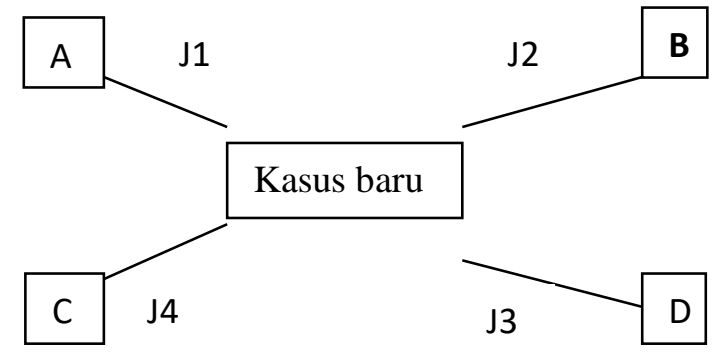

Adapun rumus yang digunakan dalam perhitungan kedekatan (similarity) adalah sebagai berikut.(Oktaviani, dkk, 2011) :

$$
\begin{aligned}
& \text { similarity(problem, case) } \\
& =\frac{s 1 * w 1+s 2 * w 2+\cdots+\text { sn } * w n}{w 1+w 2+\cdots+w n}
\end{aligned}
$$

Keterangan :

$$
\begin{aligned}
& \mathrm{S}=\operatorname{similarity(nilai~kemiripan)} \\
& \mathrm{W}=\text { weght ( bobot yang diberikan) }
\end{aligned}
$$

\section{KREDIT}

Kredit merupakan suatu fasilitas keuangan yang memungkinkan seseorang atau badan usaha untuk meminjam uang untuk membeli produk dan membayarnya kembali dalam waktu yang ditentukan.

\section{HASIL DAN PEMBAHASAN}

Pada penelitian ini, melakukan analisa kemiripan data antar hasil observasi atau pemohon memberikan data langsung dan hasil wawancara (interview) terhadap pemohon Dari hasil observasi yang telah dilakukan pada bank CIMB NIAGA terdapat data kualitatif, yang dimana data ini merupakan data penilaian kelayakan pemberian kredit kepada nasabah. Untuk mengukur jarak masing-masing atribut, perlu diberikan bobot. Bobot yang diberikan, nilainya antara 0 dan 1 , dimana 0 menandakan atribut tidak berpengaruh dan 1 menandakan atribut sangat berpengaruh. Pemberian bobot pada masing-masing atribut dapat dilihat pada tabel berikut :

Tabel 1 Bobot Masing-masing prediktor

\begin{tabular}{|l|l|l|}
\hline No & Atribut & Bobot \\
\hline 1 & Limit & 0.8 \\
\hline 2 & Usia & 0.8 \\
\hline 3 & Pekerjaan & 0.8 \\
\hline 4 & Penghasilan Minimum Setahun & 0.8 \\
\hline 5 & Jenis Kartu Kredit CIMB Niaga & 0.6 \\
\hline 6 & Kondisi debitur & 0.5 \\
\hline
\end{tabular}

Kedekatan nilai atribut limit di tunjukkan ditabel berikut :

Tabel 2 klasifikasi nilai limit pengajuan

\begin{tabular}{|l|l|l|l|}
\hline No & Limit & Nilai & Bobot \\
\hline 1 & 5.000 .000 & 100 & \multirow{2}{*}{0.8} \\
\hline 2 & 20.000 .000 & 80 & \\
\hline 3 & 50.000 .000 & 60 & \\
\hline 4 & 10.000 .000 & 50 & \\
\hline \multicolumn{2}{r|}{ Setelah dilakukan } & klasifikasi pengajuan \\
\hline
\end{tabular}
limit, berikutnya melakukan kedekatan atribut limit yaitu dilihat pada tabel berikut :

Tabel 3 Kedekatan nilai atribut limit

\begin{tabular}{|l|l|l|l|l|}
\hline No & 1 & 2 & 3 & 4 \\
\hline 1 & 1 & 0.8 & 0.6 & 0.5 \\
\hline 2 & 0.8 & 1 & 0.75 & 0.571 \\
\hline 3 & 0.6 & 0.75 & 1 & 0.857 \\
\hline 4 & 0.5 & 0.7 & 0.75 & 1 \\
\hline
\end{tabular}

Kedekatan nilai atribut Usia di tunjukkan pada tabel berikut ini :

Tabel 4 Klasifikasi Usia

\begin{tabular}{|l|l|l|l|}
\hline No & Usia & Nilai Atribut & Bobot \\
\hline 1 & 17 tahun & 100 & \multirow{2}{*}{0.8} \\
\hline 2 & 30 tahun & 70 & \\
\hline 3 & 60 tahun & 40 & \\
\hline 4 & 40 tahun & 30 & \\
\hline
\end{tabular}

Setelah dilakukan klasifikasi Usia, berikutnya melakukan pencarian nilai kedekatan atribut usia yaitu dilihat pada tabel berikut :

Tabel 5 kedekatan nilai atribut Usia

\begin{tabular}{|l|l|l|l|l|}
\hline No & 1 & 2 & 3 & 4 \\
\hline 1 & 1 & 0.7 & 0.4 & 0.3 \\
\hline 2 & 0.7 & 1 & 0.571 & 0.357 \\
\hline 3 & 0.4 & 0.7 & 1 & 0.610 \\
\hline 4 & 0.3 & 0.357 & 0.610 & 1 \\
\hline
\end{tabular}

Kedekatan nilai atribut Pekerjaan di tunjukkan pada tabel berikut ini : 
Tabel 6 Klasifikasi Pekerjaaan

\begin{tabular}{|l|l|l|l|}
\hline No & Pekerjaan & Nilai Atribut & Bobot \\
\hline 1 & Pegawai Swasta & 100 & \multirow{2}{*}{0.8} \\
\cline { 1 - 2 } 2 & Pegawai negeri & 90 & \\
\hline 3 & Wiraswasta & 80 & \\
\hline 4 & Mahasiswa & 70 & \\
\hline 5 & Ibu rumah tangga & 60 & \\
\cline { 1 - 2 } & &
\end{tabular}

Setelah dilakukan klasifikasi Pekerjaan, berikutnya melakukan pencarian nilai kedekatan atribut pekerjaan yaitu dapat dilihat pada tabel berikut :

Tabel 7 Kedekatan nilai atribut pekerjaan

\begin{tabular}{|l|l|l|l|l|l|}
\hline No & 1 & 2 & 3 & 4 & 5 \\
\hline 1 & 1 & 0.9 & 0.8 & 0.7 & 0.6 \\
\hline 2 & 0.9 & 1 & 0.889 & 0.778 & 0,667 \\
\hline 3 & 0.8 & 0.889 & 1 & 0.875 & 0.75 \\
\hline 4 & 0.7 & 0.778 & 0.875 & 1 & 0.857 \\
\hline 5 & 0.6 & 0.667 & 0.75 & 0.857 & 1 \\
\hline
\end{tabular}

Kedekatan nilai atribut Penghasilan ditunjukkan pada tabel berikut ini :

Tabel 8 Klasifikasi penghasilan

\begin{tabular}{|l|l|l|l|}
\hline No & $\begin{array}{l}\text { Penghasilan } \\
\text { Minimum/tahun }\end{array}$ & Nilai & Bobot \\
\hline 1 & 36.000 .000 & 100 & \\
\cline { 1 - 3 } 2 & 60.000 .000 & 70 & \multirow{2}{*}{0.8} \\
\cline { 1 - 3 } & 90.000 .000 & 40 & \\
\hline 4 & 300.000 .000 & 60 & \\
\hline 5 & 450.000 .000 & 50 & \\
\hline
\end{tabular}

Setelah dilakukan klasifikasi Pekerjaan, berikutnya melakukan pencarian nilai kedekatan atribut pekerjaan yaitu dapat dilihat pada tabel berikut

Tabel 9 Kedekatan nilai atribut penghasilan

\begin{tabular}{|l|l|l|l|l|l|}
\hline No & 1 & 2 & 3 & 4 & 5 \\
\hline 1 & 1 & 0.7 & 0.4 & 0.6 & 0.5 \\
\hline 2 & 0.7 & 1 & 0.571 & 0,667 & 0.556 \\
\hline 3 & 0.4 & 0.875 & 1 & 0.75 & 0.625 \\
\hline 4 & 0.7 & 0.778 & 0.875 & 1 & 0.714 \\
\hline 5 & 0.6 & 0.667 & 0.75 & 0.5 & 1 \\
\hline
\end{tabular}

Kedekatan nilai atribut Jenis kartu di tunjukkan pada tabel berikut ini :
Tabel 10 klasifikasi Jenis kartu kredit

\begin{tabular}{|l|l|l|l|}
\hline No & Atribut & Nilai & \multirow{2}{*}{ Bobot } \\
\hline 1 & CIMB Niaga classic & 100 & \multirow{2}{*}{0,6} \\
\cline { 1 - 2 } 2 & CIMB Niaga Gold & 70 & \\
\hline 3 & CIMB Niaga Platinum & 60 & \\
\hline 4 & CIMB Niaga Infinite & 50 & \\
\hline 5 & CIMB Niaga World & 40 & \\
\cline { 1 - 2 } & &
\end{tabular}

Setelah dilakukan klasifikasi jenis kartu kredit, berikutnya melakukan pencarian nilai kedekatan atribut jenis kartu kredit yaitu dapat dilihat pada tabel berikut :

Tabel 11 Kedekatan nilai atribut jenis kartu kredit

\begin{tabular}{|l|l|l|l|l|l|}
\hline No & 1 & 2 & 3 & 4 & 5 \\
\hline 1 & 1 & 0.7 & 0.6 & 0.5 & 0.4 \\
\hline 2 & 0.7 & 1 & 0,667 & 0,667 & 0.556 \\
\hline 3 & 0.6 & 0.875 & 1 & 0.75 & 0.625 \\
\hline 4 & 0.5 & 0.778 & 0.875 & 1 & 0.714 \\
\hline 5 & 0.4 & 0.667 & 0.75 & 0.5 & 1 \\
\hline
\end{tabular}

Kedekatan nilai atribut Jenis kondisi debitor di tunjukkan pada tabel berikut ini

Tabel 12 klasifikasi kondisi debitor

\begin{tabular}{|l|l|l|l|}
\hline No & Atribut kondisi debitor & Nilai & Bobot \\
\hline 1 & Cukup Baik & 100 & \multirow{2}{*}{0,6} \\
\hline 2 & Baik & 70 & \\
\hline 3 & Sangat Baik & 40 & \\
\cline { 1 - 2 } & &
\end{tabular}

Setelah dilakukan klasifikasi Kondisi Debitur, berikutnya melakukan pencarian nilai kedekatan atribut Kondisi Debitur yaitu dilihat pada tabel berikut :

Tabel 13 kedekatan nilai atribut kondisi debitur

\begin{tabular}{|l|l|l|l|}
\hline No & 1 & 2 & 3 \\
\hline 1 & 1 & 0.7 & 0.4 \\
\hline 2 & 0.7 & 1 & 0.571 \\
\hline 3 & 0.4 & 0.571 & 1 \\
\hline
\end{tabular}

Setelah menentukan kedekatan nilai atribut dari masing-masing atribut prediktor,

Tabel 14 Sample Data trainining

\begin{tabular}{|l|l|l|l|l|l|l|l|}
\hline No & Limit & Usia & Pekerjaan & $\begin{array}{l}\text { Penghasilan } \\
\text { /tahun }\end{array}$ & $\begin{array}{l}\text { Jenis Kartu } \\
\text { Kredit }\end{array}$ & $\begin{array}{l}\text { Kondisi } \\
\text { Debitor }\end{array}$ & Resiko \\
\hline 1 & 5.000 .00 & 30 & $\begin{array}{l}\text { Pegawai } \\
\text { swasta }\end{array}$ & 36.000 .000 & $\begin{array}{l}\text { CIMB Niaga } \\
\text { classic }\end{array}$ & $\begin{array}{l}\text { Cukup } \\
\text { baik }\end{array}$ & Sedang \\
\hline 2 & 20.000 .00 & 40 & wiraswata & 90.000 .000 & $\begin{array}{l}\text { CIMB Niaga } \\
\text { Platinum }\end{array}$ & Baik & Tinggi \\
\hline 3 & 10.000 .000 & 60 & $\begin{array}{l}\text { Pegawai } \\
\text { Swasta }\end{array}$ & 300.000 .000 & $\begin{array}{l}\text { CIMB Niaga } \\
\text { infinite }\end{array}$ & $\begin{array}{l}\text { Sangat } \\
\text { baik }\end{array}$ & rendah \\
\hline
\end{tabular}


Misalkan ada kasus baru pada data testing dengan nilai atribut seperti pada Tabel 17. Kasus baru tersebut akan dihitung kedekatannya dengan kasus lama yang terdapat pada data training table 14 .

Tabel 15 Data testing

\begin{tabular}{|l|l|l|l|l|l|}
\hline No & $\begin{array}{l}\text { Pengajuan } \\
\text { Limit }\end{array}$ & Usia & Pekerjan & $\begin{array}{l}\text { Peng } \\
\text { hasilan }\end{array}$ & $\begin{array}{l}\text { Kondisi } \\
\text { Debitor }\end{array}$ \\
\hline 4 & 10.000 .000 & 17 & $\begin{array}{l}\text { Pegawai } \\
\text { swasta }\end{array}$ & $\begin{array}{l}300.000 . \\
000\end{array}$ & baik \\
\hline
\end{tabular}

Perhitungan kedekatan kasus baru pada data testing pada Tabel 18 dengan 3 kasus lama pada data training pada Tabel 4.17, yaitu:

1. Kedekatan kasus baru dengan kasus nomor 1

Tabel 16 Kasus 1

\begin{tabular}{|l|l|l|l|l|l|}
\hline No & Atribut & $\begin{array}{l}\text { Nilai atribut } \\
\text { kasus nomor 1 }\end{array}$ & $\begin{array}{l}\text { Nilai atribut } \\
\text { kasus baru }\end{array}$ & $\begin{array}{l}\text { Kedek } \\
\text { atan } \\
\text { (a) }\end{array}$ & Bobot (b) \\
\hline 1 & Limit & 10.000 .000 & 10.000 .000 & 1 & 0.8 \\
\hline 2 & Usia & 60 & 17 & 0.5 & 0.8 \\
\hline 3 & Pekerjaan & $\begin{array}{l}\text { Pegawai } \\
\text { Swasta }\end{array}$ & $\begin{array}{l}\text { Pegawai } \\
\text { Swasta }\end{array}$ & 1 & 0.8 \\
\hline 4 & $\begin{array}{l}\text { Penghasilan } \\
\text { Minimum Setahun }\end{array}$ & 36.000 .000 & 300.000 .000 & 0.6 & 0.8 \\
\hline 5 & $\begin{array}{l}\text { Jenis Kartu Kredit } \\
\text { CIMB Niaga }\end{array}$ & $\begin{array}{l}\text { CIMB Niaga } \\
\text { infinite }\end{array}$ & $\begin{array}{l}\text { CIMB Niaga } \\
\text { world }\end{array}$ & 0.5 & 0.6 \\
\hline 6 & Kondisi debitur & Sangat baik & baik & 0.571 & 0.6 \\
\hline
\end{tabular}

Dari tabel diatas, dapat dihitung kedekatan kasus baru dengan kasus nomor 1, dengan cara :

Similarity $=$

$((\mathrm{a} 1 * \mathrm{~b} 1)+(\mathrm{a} 2 * \mathrm{~b} 2)+(\mathrm{a} 3 * \mathrm{~b} 3)+(\mathrm{a} 4 * \mathrm{~b} 4)+(\mathrm{a} 5 * \mathrm{~b} 5)+(\mathrm{a} 6 * \mathrm{~b}$

6)) / (b1+b2+b3+b4+b5+b6+b7)
Similarity $=((1 * 0.8)+(0.5 * 0.8)+(1 * 0.8)+(0.6 * 0.8)+(0$ $.5 * 0.6)+(0.571 * 0.6)) /(0.8+0.8+0.8+0.8+0.6+0.6)$

Similarity $=\mathbf{0 . 7 0 9 6 8}$

2. Kedekatan kasus baru dengan kasus nomor 2

Tabel 17 Kasus 2

\begin{tabular}{|l|l|l|l|l|l|}
\hline No & Atribut & $\begin{array}{l}\text { Nilai atribut } \\
\text { kasus nomor 1 }\end{array}$ & $\begin{array}{l}\text { Nilai atribut } \\
\text { kasus baru }\end{array}$ & $\begin{array}{l}\text { Kedekatan } \\
\text { (a) }\end{array}$ & $\begin{array}{l}\text { Bobot } \\
\text { (b) }\end{array}$ \\
\hline 1 & Limit & 5.000 .00 & 10.000 .000 & 0.5 & 0.8 \\
\hline 2 & Usia & 30 & 17 & 0.7 & 0.8 \\
\hline 3 & Pekerjaan & Wiraswata & Pegawai Swasta & 0.8 & 0.8 \\
\hline 4 & $\begin{array}{l}\text { Penghasilan } \\
\text { Minimum Setahun }\end{array}$ & 36.000 .000 & 300.000 .000 & 0.6 & 0.8 \\
\hline 5 & $\begin{array}{l}\text { Jenis Kartu Kredit } \\
\text { CIMB Niaga }\end{array}$ & $\begin{array}{l}\text { CIMB Niaga } \\
\text { classic }\end{array}$ & $\begin{array}{l}\text { CIMB Niaga } \\
\text { world }\end{array}$ & 0.714 & 0.6 \\
\hline 6 & Kondisi debitur & Cukup baik & baik & 0.4 & 0.6 \\
\hline
\end{tabular}

Kedekatan kasus baru dengan kasus nomor 3

Dari tabel diatas, dapat dihitung kedekatan kasus baru dengan kasus nomor 3, dengan cara :

Similarity $=$ $((\mathrm{a} 1 * \mathrm{~b} 1)+(\mathrm{a} 2 * \mathrm{~b} 2)+(\mathrm{a} 3 * \mathrm{~b} 3)+(\mathrm{a} 4 * \mathrm{~b} 4)+(\mathrm{a} 5 * \mathrm{~b} 5)+(\mathrm{a} 6 * \mathrm{~b}$

6)) / (b1+b2+b3+b4+b5+b6+b7)
Similarity $=((0.5 * 0.8)+(0.7 * 0.8)+(0.8 * 0.8)+(0.6 * 0.8)$ $+(0.714 * 0.6)+(0.4 * 0.6)) /$ $(0.8+0.8+0.8+0.8+0.6+0.6)$

Similarity $=\mathbf{0 . 6 2 4 6 4}$. 
Tabel 17 Data Kasus 3

\begin{tabular}{|l|l|l|l|l|l|}
\hline $\begin{array}{c}\text { N } \\
\mathrm{o}\end{array}$ & Atribut & $\begin{array}{l}\text { Nilai atribut kasus } \\
\text { nomor 1 }\end{array}$ & $\begin{array}{l}\text { Nilai atribut kasus } \\
\text { baru }\end{array}$ & Kedekatan (a) & Bobot (b) \\
\hline 1 & Limit & 20.000 .00 & 10.000 .000 & 0.75 & 0.8 \\
\hline 2 & Usia & 40 & 17 & 0.3 & 0.8 \\
\hline 3 & Pekerjaan & wiraswata & Pegawai Swasta & 0.8 & 0.8 \\
\hline 4 & $\begin{array}{l}\text { Penghasilan Minimum } \\
\text { Setahun }\end{array}$ & 90.000 .000 & 300.000 .000 & 0.875 & 0.8 \\
\hline 5 & $\begin{array}{l}\text { Jenis Kartu Kredit } \\
\text { CIMB Niaga }\end{array}$ & $\begin{array}{l}\text { CIMB Niaga } \\
\text { Platinum }\end{array}$ & $\begin{array}{l}\text { CIMB Niaga } \\
\text { world }\end{array}$ & 0.75 & 0.6 \\
\hline 6 & Kondisi debitur & Baik & baik & 1 & 0.6 \\
\hline
\end{tabular}

Similarity $=$

$((a 1 * b 1)+(a 2 * b 2)+(a 3 * b 3)+(a 4 * b 4)+(a 5 * b 5)+(a 6 * b$

6)) / (b1+b2+b3+b4+b5+b6+b7)

Similarity $=((0.75 * 0.8)+(0.3 * 0.8)+(0.8 * 0.8)+(0.875 *$

$0.8)+(0.75 * 0.6)+(1 * 0.6)) /$

$(0.8+0.8+0.8+0.8+0.6+0.6)$

Similarity $=\mathbf{0 . 7 3 4 0 9}$

Melihat dari ke tiga kasus tersebut, maka yang mempunyai nilai tertinggi adalah kasus ketiga, melihat dari kasus yang tertinggi bahwa kasus itulah yang merupakan kasus yang terdekat dengan kasus baru. Berarti yang mendekati dengan kasus baru adalah kasus ke tiga. Maka klasifikasi resiko pemberian kartu kredit pada kasus baru adalah Rendah

\section{Implementasi Sistem}

Pada tahap implementasi, dilakukan dengan beberapa langkah yaitu sebagai berikut

1. Pembobotan

berikut ini adalah merupakan tahap awal penginputan data pada form pembobotan setiap atribut dapat dilihat pada tabel berikut.

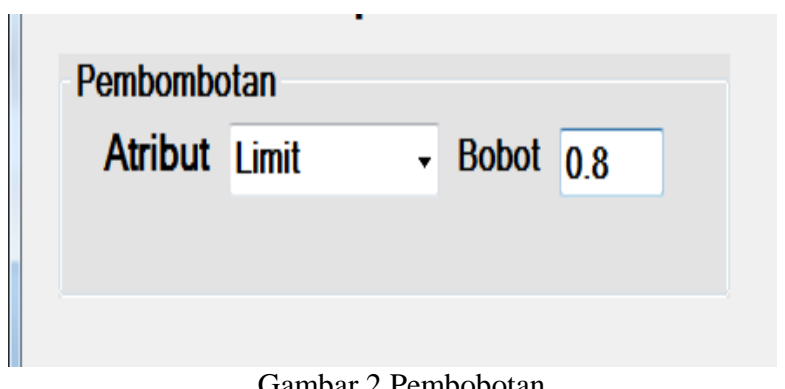

Gambar 2 Pembobotan

\section{Klasifikasi atribut}

berikut ini adalah proses klasifikasi atribut, dapat dilihat pada gambar berikut ini :

\begin{tabular}{|c|c|}
\hline Klasifikasi & \\
\hline Jenis atribut & Limit \\
\hline ISI & 5.000000 \\
\hline nilai & 100 \\
\hline Bobot & 0.8 \\
\hline
\end{tabular}

Gambar 3 Klasifikasi

3. Data Training

Berikut ini merupakan data training yang akan dilakukan perhitngan kedekatan terhadap kasus baru. Dapat dilihat pada gambar berikut :

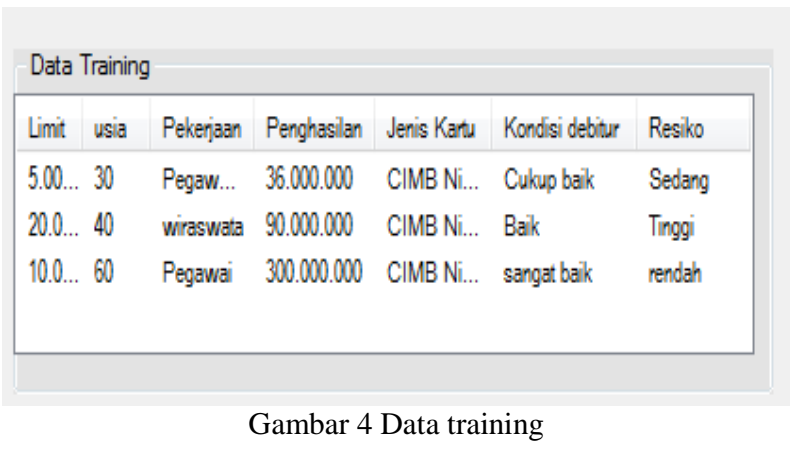

\section{Data Testing}

Data testing merupakan kasus baru yang akan menjadi kedekatan atribut, adapat dilihat pada gambar berikut ini ;

Data Testing

Limi usia Pekerjaan Penghasian Jenis Kanu Kondisi debiur

10.0... 17 Pegaw... 300.000.000 CIMB Ni... bak

Gambar 5 Data testing 


\section{Hasil kedekatan}

Berikut ini merupakan tampilan hasil kedekatan kasus setelah dilakukan pendekatan dari kasus baru dengan kasus lama, dapat dilihat tabel berikut ini ;

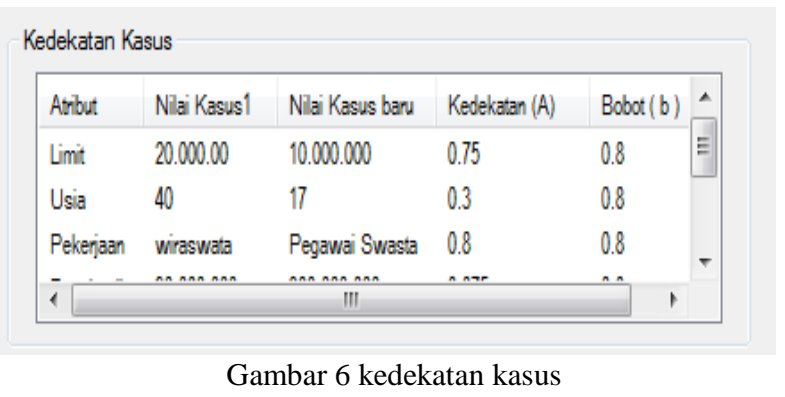

6. Tampilan Hasil

Berikut hasil hasil keseluruhan dan tampilan form keseluruhan, dapat dilihat pada gambar berikut ini

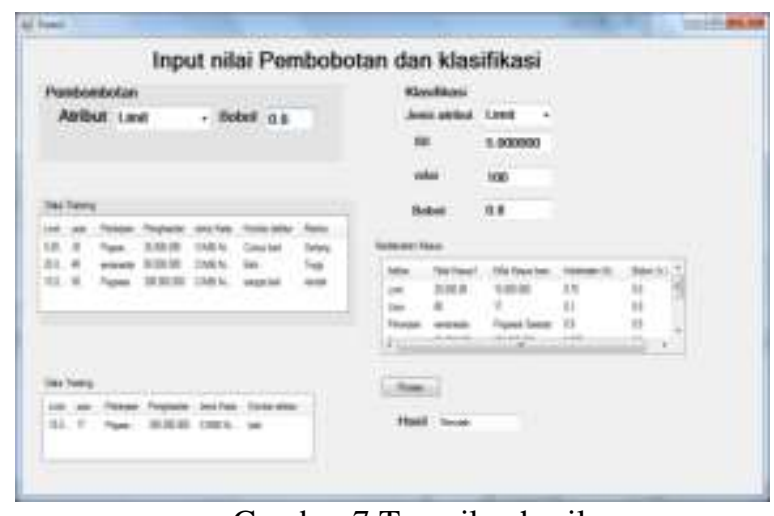

Gambar 7 Tampilan hasil

\section{PENUTUP}

Berdasarkan uraian dari penelitian diatas, dapat menarik kesimpulan sebagai berikut:

1. Pada hasil proses prediksi kelayakan penerimaan kartu kredit pada bank CIMB niaga selama ini masih belum akurat

2. Algoritma Nearest Neighbor mampu memberikan solusi untuk mempredikasi kelayakan penerimaan kartu kredit pada bank CIMB Niaga

3. Penggunaan aplikasi prediksi kelayakan penerimaan kartu kredit pada CIMB Niaga lebih efesien dan efektf.

Berdasarkan kelemahan dan kelebihan dari penelitian ini, maka dibrikan saran sebagai berikut:

1. Agar lebih mudah untuk melakukan analisis data nasabah lebih baik membangun aplikasi berbasis android.

2. Di sarankan kepada penelitian berikutnya agar dapat menggunakan metode yang lainnya yang ada dalam data mining.
1. Diharapkan untuk pengembangan aplikasi yang lebih efesien dengan metode yang lain dalam melakukan prediksi kelayakan nasabah.

\section{DAFTAR PUSTAKA}

[1] R. S. Lubis, "Data Mining Pengarsipan Dokumen Berdasarkan Kontrak Kerja Dengan Metode Alphabetic," Inf. dan Teknol. Ilm., vol. 4, no. September, pp. 161-166, 2014.

[2] H. D. Honesqi, "Klasifikasi Data Mining Untuk Menentukan Tingkat Persetujuan Kartu Kredit," J. Teknoif, vol. 5, no. 2, pp. 57-62, 2017, doi: 10.21063/jtif.2017.v5.2.57-62.

[3] R. L. Angga Ginanjar Mabrur, "PENERAPAN DATA MINING UNTUK MEMPREDIKSI Program Studi Teknik Informatika Jurnal Komputer dan Informatika ( KOMPUTA )," J. Komput. dan Inform., vol. 1, pp. 53-57, 2012.

[4] E. Ndruru, "Pemanfaatan Sistem Pendukung Keputusan Dalam Seleksi Pkw Terbaik Dengan Metode Aras Pada Lpk2-Pascom Medan," vol. I, no. 2, pp. 26-34, 2019

[5] M. Reza Noviansyah, T. Rismawan, D. Marisa Midyanti, J. Sistem Komputer, and F. H. MIPA Universitas Tanjungpura Jl Hadari Nawawi, "Penerapan Data Mining Menggunakan Metode KNearest Neighbor Untuk Klasifikasi Indeks Cuaca Kebakaran Berdasarkan Data Aws (Automatic Weather Station) (Studi Kasus: Kabupaten Kubu Raya)," J. Coding, Sist. Komput. Untan, vol. 6, no. 2, pp. 48-56, 2018.

[6] E. Ndruru, "Penerapan Algoritma C4 . 5 dalam Memprediksi Dampak Kebakaran Hutan bagi Kesehatan," 2019.

[7] M. Ridwan, H. Suyono, and M. Sarosa, "Penerapan Data Mining Untuk Evaluasi Kinerja Akademik Mahasiswa Menggunakan Algoritma Naive Bayes Classifier," Eeccis, vol. 7, no. 1, pp. 59-64, 2013, doi: 10.1038/hdy.2009.180.

[8] P. Studi, T. Industri, F. Teknik, U. Mulawarman, and N. Neighbour, A Suryani, Deasy Kartika Rahayu Kuncoro , Lina Dianati Fathimahhayati pemasaran . Distribusi dapat diartikan s," vol. 6, no. 1, pp. 41-49, 2018.

[9] T. I. Barokah and Y. I. Kurniawan, "Aplikasi Klasifikasi Penentuan Pengajuan Kartu Kredit Menggunakan Metode K-Nearest Neighbor Di Bank Bni Syariah Surabaya," Komputa J. Ilm. Komput. dan Inform., vol. 8, no. 1, pp. 36-43, 2019, doi: 10.34010/komputa.v8i1.3047.

[10] P. T. J. Putera, W. Ode, N. Kadir, and B. Pramono, "Penerapan data," vol. 5, no. 1, pp. 97-104, 2019.

[11] E. Ndruru and T. Zebua, "Application of Text Message Held in Image Using Combination of Least Significant Bit Method and One Time Pad," IJCCS (Indonesian J. Comput. Cybern. Syst., vol. 13, no. 4, p. 323, 2019, doi: 10.22146/ijccs.46401.

[12] E. Ndruru, "Penerapan Metode Certainty Factor Dalam Mendiagnosa Penyakit Cacar Pada Kulit Manusia," J. Armada Inform., vol. 3, no. 1, pp. 1022, 2019, doi: 10.36520/jai.v3i1.44 